\title{
Postprandial Acid Reflux is Reduced by Delayed Gastric Emptying
}

\author{
Yoshinori YAMASHITA ${ }^{1}$, Rodney J. MASON ${ }^{2}$ and Tom R. DEMEESTER ${ }^{2}$ \\ ${ }^{1}$ Department of Surgery, Hiroshima City Asa Hospital, Hiroshima, Japan \\ ${ }^{2}$ Department of Surgery, University of Southern California, School of Medicine, Los \\ Angeles, California, USA
}

\begin{abstract}
The aim of this study was to investigate influence of delayed gastric emptying on postprandial reflux in esophageal $\mathrm{pH}$. Sixty-nine consecutive patients underwent 24 hour (h) esophageal $\mathrm{pH}$ monitoring and gastric emptying. In $24 \mathrm{~h}$ esophageal $\mathrm{pH}$ monitoring, \% postprandial reflux $\mathrm{pH}<4$ for $2 \mathrm{~h}$ after each meal (\% PRT) was extracted from the $24 \mathrm{~h} \mathrm{pH}$ profile. After solid test meal ( $1 \mathrm{mCi}, \mathrm{Tc} 99 \mathrm{~m})$ was given, gastric emptying was measured with a gamma detector placed transnasally $5 \mathrm{~cm}$ below lower esophageal sphincter. \% PRT was similar among the 34 normal, 26 delayed and 9 rapid gastric emptying rate patients. Thirty-five with a positive $\mathrm{pH}$ study and 34 with a negative had a similar prevalence of gastric emptying disorder. In the positive $\mathrm{pH}$ study group, patients with normal gastric emptying had significantly higher \% PRT than those with delayed gastric emptying (22.0 vs $12.1 \%, \mathrm{P}<0.05)$. In the same population, patients with a normal \%PRT had a significantly higher prevalence of delayed gastric emptying compared with those with a positive $\%$ PRT (6/8 vs $9 / 27, \mathrm{P}<0.05)$. In patient with abnormal acid exposure but normal \% PRT on $24 \mathrm{~h}$ esophageal $\mathrm{pH}$ monitoring, gastric emptying may be delayed.
\end{abstract}

Key words: reflux esophagitis, postprandial reflux, gastric emptying

\section{Introduction}

The relationship between esophageal $\mathrm{pH}$ evidence and gastric emptying is still controversial, although both tests are generally used in the evaluation for foregut abnormality. Gastroenterologists can consider that gastric distension may explain increased acid exposure. Several authors have concluded that there is no direct link between esophageal $\mathrm{pH}$ and gastric emptying findings with radionuclides (Schwizer et al., 1989; Ewer et al., 1994; Benini et al., 1996). However, a delay in gastric emptying is frequently found in patients with gastroesophageal reflux disease (GERD) (Lundell et al., 1994; Benini et al., 1996). At present, delayed gastric emptying seems to play a role in only a minority of GERD patients (Cadiot et al., 1997). On the other hand, evaluation of postprandial reflux is still under investigation and

Correspondence to: Y. Yamashita, Department of Surgery, Hiroshima City Asa Hospital, Kabeminami 2-1-

1, Asakita-ku, Hiroshima 731-0293, Japan

Phone: +81-82-815-5211 Fax: +81-82-814-1791 e-mail: yosy.811kob@k3.dion.ne.jp 
delicate for the precise diagnosis of GERD in the literature (Gillen et al., 1994; Mason et al., 1998). It could be postulated that the degree of postprandial reflux is more directly affected by gastric emptying. To clarify the mechanisms of postprandial reflux in patients with GERD, we investigated the interaction between the two standard functional tests for the two neighboring foregut organs.

\section{Patients and Methods}

\section{Patients}

Sixty-nine consecutive patients with foregut symptoms underwent both 24 hour (h) esophageal $\mathrm{pH}$ monitoring and ambulatory gastric emptying test. Patients who had undergone major gastrointestinal surgery were excluded, but 14 patients with antireflux surgery, 5 with cholecystectomy, 1 with splenectomy and 2 with diabetes mellitus were included. The two procedures were carried out intermittently within a week.

\section{Postprandial reflux on ambulatory esophageal pH study}

Lower esophageal sphincter (LES) status was manometrically measured in all patients following an overnight fast before ambulatory esophageal $\mathrm{pH}$ monitoring. A glass esophageal $\mathrm{pH}$ probe (Ingold, Urdorf, Switzerland) was placed through the nose $5 \mathrm{~cm}$ above the upper border of the LES. Esophageal $\mathrm{pH}$ was recorded on a portable digital data recorder and analyzed as described previously (Synectics Inc, Minneapolis, Minn.) (Jamiesen et al., 1992). The $\%$ time $\mathrm{pH}<4$ and its positive rate were compared simultaneously with postprandial reflux. Percentage postprandial reflux time $\mathrm{pH}<4$ for $2 \mathrm{hs}$ after each meal (\%PRT) was extracted from 24 $\mathrm{h} \mathrm{pH}$ profile by the following formula.

$\% \mathrm{PRT}=$ postprandial reflux time $\mathrm{pH}<4 /$ total time of postprandial period $\times 100$

Normal value of $\%$ PRT was determined to be $8.4 \%$ as the 95 th percentile value of 94 normal volunteers.

\section{Ambulatory gastric emptying test}

An ambulatory gamma detection probe (RMD model, Synectics Medical, Watertown, MA) was used for more precise study, in which the probe was placed transnasally $5 \mathrm{~cm}$ below the lower border of the LES. Fundic emptying was measured twice, once each in the sitting position and ambulatory upright position as gastric emptying after two solid test meals of Tc 99m-labeled egg sandwiches $(1 \mathrm{mCi})$ were given. The digital data recorder was carried on a belt around the subject's waist (Digitrapper, Synectics Medical). If either of the two gastric emptying studies showed a delay, the patient was regarded as delayed. Thirty healthy volunteers qualified for the study (Ritter et al., 1997). Pathological gastric emptying was set as values outside the 5th and 95th percentile values of healthy volunteers.

\section{Statistical analysis}

Data show mean \pm standard deviation. Statistical analysis was done by one-way analysis of 
Table 1 Esophageal acid exposure according to ambulatory fundic emptying findings

\begin{tabular}{cllll}
\hline Number of patients & $\begin{array}{c}\text { Fundic emptying } \\
\text { normal } \\
34\end{array}$ & \multicolumn{1}{c}{$\begin{array}{c}\text { 26 } \\
\text { rapid } \\
9\end{array}$} & ANOVA \\
\hline Esophageal $\mathrm{pH}$ & & & & \\
\% time $\mathrm{pH}<4$ & $3.99 \pm 5.38$ & $5.16 \pm 6.42$ & $4.56 \pm 4.61$ & N.S. \\
Positive rate & $47.1(16 / 34)$ & $53.8(14 / 26)$ & $55.6(5 / 9)$ & N.S. \\
\% PRT & $11.6 \pm 14.0$ & $7.73 \pm 9.46$ & $12.7 \pm 12.9$ & N.S. \\
Positive rate & $41.2(14 / 34)$ & $38.5(10 / 26)$ & $55.6(5 / 9)$ & N.S. \\
\hline
\end{tabular}

variance (ANOVA), Student's t and Fisher's exact tests using the SPSS statistical software package (SPSS Inc., Chicago, IL). A value of less than 0.05 was considered statistically significant.

\section{Results}

Sixty-nine cases were classified as 34 normal, 26 delayed, and 9 rapid gastric emptying (Table 1). The $\%$ time $\mathrm{pH}<4$ of the normal, delayed and rapid emptying groups were $3.99 \pm 5.38$, $5.16 \pm 6.42$ and $4.56 \pm 4.61$, respectively, showing no significant difference between them $(\mathrm{p}=0.73)$. The \% PRT was also similar in all three groups $(11.6 \pm 14.0,7.73 \pm 9.46,12.7 \pm 12.9$, $\mathrm{p}=0.51$ ). Further, both the positive rate of esophageal $\mathrm{pH}$ and that of $\%$ PRT were also similar among the three groups according to the findings of gastric emptying (Table 1).

With regard to esophageal $\mathrm{pH}$ status, two populations were identified, 35 patients with a positive $\mathrm{pH}$ study and 34 patients with negative values. The prevalence of delay in gastric emptying in the $\mathrm{pH}$ study negative and positive groups was 12 (35.3\%) and 14 patients (40.0\%), respectively (Table 2). Patients are also divided into another two populations, 40 with a negative and 29 with a positive \% PRT. The prevalence of delay in gastric emptying in these two groups was $16(40.0 \%)$ and 10 patients (34.5\%), respectively. There was no significant difference in these gastric emptying findings according to esophageal $\mathrm{pH}$ status (Fisher's exact test).

We further classified the two esophageal $\mathrm{pH}$ negative and positive groups into two groups each according to delay in gastric emptying with groups $1,2,3$, and 4, composed of $22,12,21$ and 14 patients, respectively. Table 3 shows the background characteristics, showing no significant differences especially in sphincter events in esophageal manometry findings. The \% PRT was also compared among the four groups as shown in Fig. 1. Groups 1 and 2, which were $\mathrm{pH}$ study negative, showed similar \% PRT despite a delay in gastric emptying $(2.11 \pm 3.50,2.62$ $\pm 5.00 \%, \mathrm{p}=0.875$ ). With regard to groups 3 and 4 , which were $\mathrm{pH}$ study positive, group 3 with no delay in gastric emptying had significantly higher \% PRT than patients with delay in group 4 $(22.0 \pm 12.8,12.1 \pm 10.8 \%, \mathrm{p}=0.022)$. There was also a significant difference in $\%$ PRT positive rate between groups 3 and $4(90 \%, 57 \%, \mathrm{p}=0.039)$.

In the esophageal $\mathrm{pH}$ positive population, there were two other groups, 8 patients who were $\%$ PRT negative and 27 who were positive. As shown in Fig. 2, the patients with negative \% PRT had a significantly higher prevalence of delayed gastric emptying compared with those with positive \% PRT (6/8 vs. 8/27, p=0.039). 
Table 2 Prevalence of fundic emptying abnormality according to ambulatory esophageal $\mathrm{pH}$ monitoring findings

\begin{tabular}{|c|c|c|c|c|}
\hline & \multicolumn{4}{|c|}{ Esophageal pH } \\
\hline & \multicolumn{2}{|c|}{$\%$ time $\mathrm{pH}<4$} & \multicolumn{2}{|c|}{ \%PRT } \\
\hline & negative & positive & negative & positive \\
\hline \multirow{5}{*}{$\begin{array}{c}\text { Fundic Emptying } \\
\text { Normal (\%) } \\
\text { Delayed (\%) } \\
\text { Rapid (\%) }\end{array}$} & \multicolumn{2}{|c|}{ N.S. } & \multicolumn{2}{|c|}{ N.S. } \\
\hline & $\Gamma$ & 1 & Г & 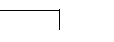 \\
\hline & $18(52.9)$ & $16(45.7)$ & $20(50.0)$ & $14(48.3)$ \\
\hline & $12(35.3)$ & $14(40.0)$ & $16(40.0)$ & $10(34.5)$ \\
\hline & $4(11.8)$ & $5(14.3)$ & $4(10.0)$ & $5(17.2)$ \\
\hline Total & 34 & 35 & 40 & 29 \\
\hline
\end{tabular}

Table 3 Patient characteristics classified into four groups by esophageal $\mathrm{pH}$ and fundic emptying findings

\begin{tabular}{|c|c|c|c|c|}
\hline \multirow{3}{*}{$\begin{array}{l}\text { Groups } \\
\text { Esophageal pH } \\
\text { Fundic emptying }\end{array}$} & 1 & 2 & 3 & 4 \\
\hline & \multicolumn{2}{|c|}{ negative } & \multicolumn{2}{|c|}{ positive } \\
\hline & no delay & delayed & no delay & delayed \\
\hline no. of cases & 22 & 12 & 21 & 14 \\
\hline mean age & 48.6 & 43.4 & 52.7 & 48.3 \\
\hline $\begin{array}{l}\text { sex (male/female) } \\
\text { manometry on average }\end{array}$ & $12 / 10$ & $7 / 5$ & $9 / 12$ & $8 / 6$ \\
\hline LESP (mmHg) & 11.4 & 7.8 & 13.1 & 11.8 \\
\hline overall length (cm) & 2.8 & 2.3 & 2.5 & 2.6 \\
\hline abd. length $(\mathrm{cm})$ & 1.5 & 1.2 & 1.3 & 1.2 \\
\hline diabetes mellitus & 0 & 0 & 1 & 1 \\
\hline
\end{tabular}

\section{Discussion}

Ambulatory esophageal $\mathrm{pH}$ monitoring has been established for the diagnosis and treatment of GERD owing to its accuracy and utility (Jamiesen et al., 1992). However, it is not still sufficient in the evaluation of symptomatic patients with GERD. Evaluation of reflux during supine period is considered helpful (DeMeester et al., 1976; Dhiman et al., 1996), but it has been reported that upright reflux is more significant than supine (Branicki et al., 1982; DeCsestecker et al., 1987). Gillen et al. (1994) indicated that the development of esophagitis was most closely correlated with postprandial reflux. Against this, exclusion of meal periods can eliminate meal-time $\mathrm{pH}$ variability without affecting postprandial acid exposure and improve the diagnosis of GERD (Wo et al., 1994). However, postprandial reflux is a dynamic indicator of sphincter competency and increases as the structural sphincter characteristics deteriorate (Mason et al., 1998). The present results show that postprandial $\mathrm{pH}$ study therefore contributes to our understanding of not only sphincter competency but also to the degree of gastric emptying as a gastric motility disorder.

At present, most commonly used and reliable technique is gastric emptying with radionuclides, in evaluation of gastric motility although details of the mechanism of gastric emptying are still under investigation. Recently, ambulatory gastric emptying with an intraluminal gamma counter probe has been developed as a more precise measurement 


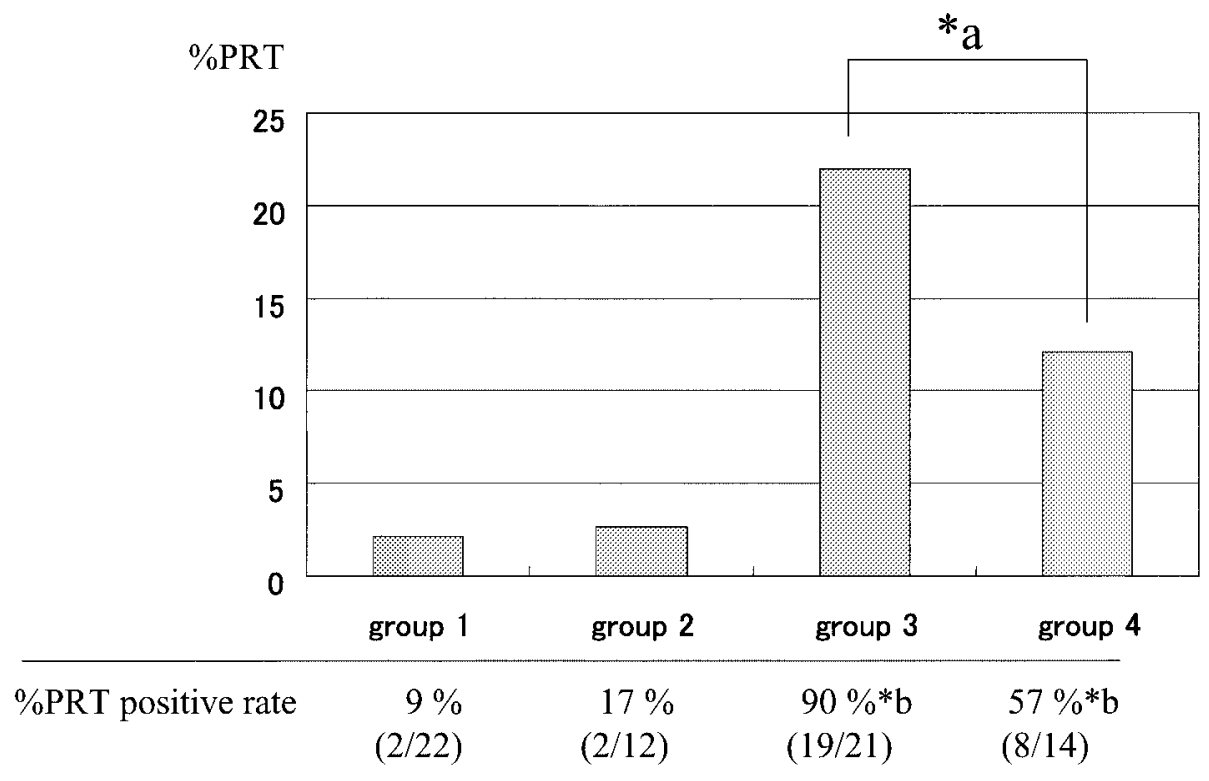

Fig. 1. Comparison of \% PRT among the four groups classified by $24 \mathrm{~h}$ esophageal $\mathrm{pH}$ monitoring and gastric emptying findings. Bars show mean \% PRT level (group 1: 2.11, group 2: 2.62, group 3: 22.0, group 4: 12.1). Significant difference is seen between groups 3 and 4 ( ${ }^{*} \mathrm{a}$ : $\mathrm{p}=0.022$ by Mann-Whitney U test, * $\mathrm{b}$ : $\mathrm{p}=0.039$ by Fisher's exact test).

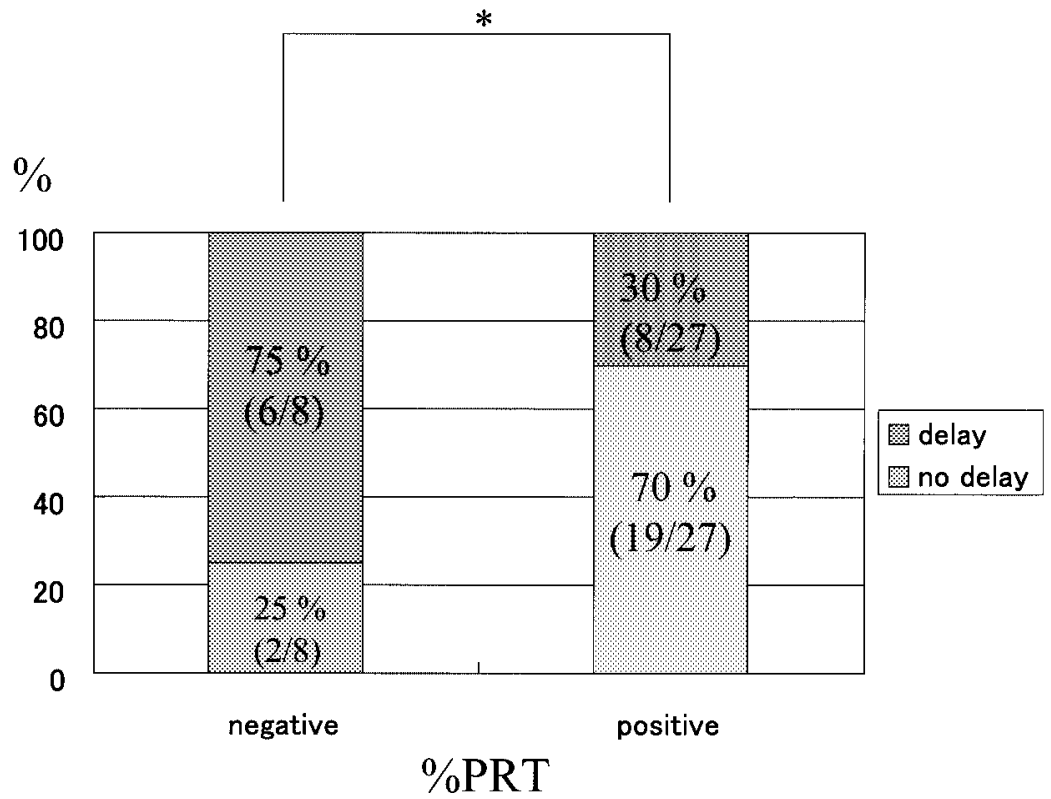

Fig. 2. Prevalence of delay in gastric emptying according to \% PRT findings in the patients with positive esophageal $\mathrm{pH}$ study. Significant difference is seen between prevalence in \% PRT positive and negative groups (*: $\mathrm{p}=0.039$ by Fisher's exact test). 
(Akkermans et al., 1994). We previously evaluated the reliability and reproducibility of ambulatory intraluminal measurement and found it to be more close to daily life and accurate means of detecting radionuclides (Ritter et al., 1997).

The relationship between gastric emptying and GER is still controversial although delayed gastric emptying is likely to increase the degree of esophageal exposure to acid. Generally speaking, it is considered that gastric emptying is significantly delayed in patients suffering from reflux symptoms (Lundell et al., 1994; Benini et al., 1996). Nevertheless, some investigators have found no relationship between esophageal $\mathrm{pH}$ events and gastric emptying (Schwizer et al., 1989; Ewer et al., 1994; Benini et al., 1996). Our data showed that patients without a delay in gastric emptying have significantly higher \% PRT than those with a delay, although they have similar LES manometry findings to patients with positive esophageal $\mathrm{pH}$ results. We concluded that normal postprandial reflux on $24 \mathrm{~h}$ esophageal $\mathrm{pH}$ profile is obviously related to delayed gastric emptying in patients with GERD. Presumably, retained food in the stomach works as a potent buffer against gastric acid (Schwizer et al., 1989). It is probable that neutral reflux may occur due to gastric distension during the meal period. To better understand the relationship between esophageal $\mathrm{pH}$ events and gastric emptying, it is necessary to monitor gastric $\mathrm{pH}$ and gastric emptying simultaneously. In fact, Stein et al. reported that delayed gastric emptying was suggested by prolonged postprandial alkalization in the gastric $\mathrm{pH}$ record (Stein et al., 1994). Delay in gastric emptying might relieve GER if the gastric acid is neutralized by food. New technique, impedance method, for measurement of neutral reflux to the esophagus, which may be more frequent in GERD patients with normal postprandial reflux on profile, should be investigated (Wenzl et al., 2002). Moreover, such neutral reflux must be distinguished from duodenogastric reflux, given that mixed reflux with duodenal juice is more harmful to the esophagus than gastric juice alone (Kaur et al., 1995).

Our results indicate that delayed gastric emptying can be predicted with $75 \%$ accuracy by normal postprandial reflux in patients with a positive esophageal $\mathrm{pH}$ study. When normal postprandial acid exposure is seen in spite of abnormal acid exposure in ambulatory esophageal $\mathrm{pH}$ monitoring, the possibility of a delay in gastric emptying should be taken into account. This also means that postprandial reflux is a useful parameter in surveying gastric dysmotility in patients with GERD. On the other hand, we previously reported that increased postprandial reflux, evaluated by the same parameter, suggests volume-induced sphincter shortening and incompetency in patient with GERD (Mason et al., 1998). Therefore, measurement of \% PRT is beneficial to patients with GERD in terms of therapy for not only GERD but also gastric dysmotility.

\section{References}

Akkermans, L.M.A. and Van Isselt, J.W. (1994). Gastric motility and emptying studies with radionuclides in research and clinical settings. Dig. Dis. Sci. 39: 95S-96S.

Benini, L., Sembenini, C., Castellani, G., Caliari, S., Fioretta, A. and Vantini, I. (1996). Gastric emptying and dyspeptic symptoms in patients with gastroesophageal reflux. Am. J. Gastroenterol. 91: 1351-1354. 
Branicki, F.J., Evans, D.F., Ogilvie, A.L., Atkinson, M. and Hardcastle, J.D. (1982). Ambulatory monitoring of oesophageal $\mathrm{pH}$ in reflux oesophagitis using a radiotelemetry system. Gut 23: 992-998.

Cadiot, G., Bruhat, A., Rigaud, D., Coste, T., Vuagnat, A, Benyedder, Y., Vallot, T., Guludec, D.L. and Mignon, M. (1997). Multivariate analysis of pathophysiological factors in reflux oesophagitis. Gut 40: 167-174.

DeCaestecker, J.S., Blackwell, J.N., Pryde, A. and Heading, R.C. (1987). Daytime gastro-esophageal reflux is important in oesophagitis. Gut 28: 519-526.

DeMeester, T.R., Johnson, L.F., Joseph, G.J., Toscano, M.S., Hall, A.W. and Skinner, D.B. (1976). Patterns of gastroesophageal reflux in health and disease. Ann. Surg. 184: 459-469.

Dhiman R.K., Saraswat V.A., Mishra A. and Naik S.R. (1996). Inclusion of supine period in short-duration pH monitoring is essential in diagnosis of gastroesophageal reflux disease. Dig. Dis. Sci. 41: 764-772.

Ewer, A.K., Durbin, G.M., Morgen, M.F. and Booth, I.W. (1994). Gastric emptying and gastroesophageal reflux in preterm infants. Arch. Dis. Child. 75: 117-121.

Gillen, P., Thornton, J, Byrne, P.J., Walsh, T.N. and Hennessy, T.P.J. (1994). Implication of upright gastro-esophageal reflux. Br. J. Surg. 81: 239-240.

Jamiesen, J.R., Stein, H.J., DeMeester, T.R., Bonavina, L., Schwizer, W., Hinder, R.A. and Albertucci, M. (1992). Ambulatory 24-h esophageal $\mathrm{pH}$ monitoring: normal values, optimal thresholds, specificity, sensitivity and reproducibility. Am. J. Gastroenterol. 87: 1102-1111.

Kauer, W.K.H., Peters, J.H., DeMeester, T.R., Ireland, A.P., Bremner, C.G. and Hagen, J.A. (1995). Mixed reflux of gastric and duodenal juice is more harmful to the esophagus than gastric juice alone. Ann. Surg. 222: 525-533.

Lundell, L.R., Myers, J.C. and Jamieson, G.G. (1994). Delayed gastric emptying and its relationship to symptoms of "gas float" after antireflux surgery. Eur. J. Surg. 160: 161-166.

Mason, J.R., Oberg, S., Bremner, C.G., Peters, J.H., Grandstatter, M., Ritter, M. and DeMeester T.R. (1998). Postprandial gastroesophageal reflux in normal volunteers and symptomatic patients. $J$. Gastrointest. Surg. 2: 342-349.

Ritter, M.P., Fein, M., DeMeester, T.R., Crooks, P.F., Peters, J.H., Gadenstatter, M., Hagen, J.A. and Bremner, C.G. (1997). Ambulatory measurement of gastric emptying is a sensitive technique in detecting abnormal gastric emptying patients. Program of 38th Annual Meeting of the Society for Surgery of the Alimentary Tract. Thorefare, pp. 60 (Abst.).

Schwizer, W., Hinder, R.A. and DeMeester, T.R. (1989). Does delayed gastric emptying contribute to gastroesophageal reflux disease? Am. J. Surg. 157: 74-81.

Stein, H.J., DeMeester, T.R., Peters, J.H. and Fuchs K.H. (1994). Technique, indications and clinical use of ambulatory 24-hour gastric $\mathrm{pH}$ monitoring in surgical practice. Surgery 116: 758-767.

Wenzl, T.G., Moroder, C., Trachterna, M., Thomson, M., Silny, J., Heimann, G. and Skopnik, H. (2002). Esophageal $\mathrm{pH}$ monitoring and impedance measurement: a comparison of two diagnostic tests for gastroesophageal reflux. J Pediatr. Gastroenterol. Nutr. 34: 511-512.

Wo, J.M. and Castell D.O. (1994). Exclusion of meal periods from ambulatory 24-hour pH monitoring may improve diagnosis of esophageal acid reflux. Dig. Dis. Sci. 39: 1601-1607.

(Received April 16, 2003; Accepted June 27, 2003) 